\title{
Expression of integrin $\beta 1$ and its significance in squamous cell carcinoma of the cervix
}

\author{
PING ZHAN ${ }^{1}$, LING LIU ${ }^{1}$, BIN LIU $^{2}$ and XI-GUANG MAO ${ }^{1}$ \\ Departments of ${ }^{1}$ Gynecology and ${ }^{2}$ Pediatrics, Affiliated Hospital of Luzhou Medical College, \\ Luzhou, Sichuan 646000, P.R. China
}

Received September 29, 2013; Accepted March 5, 2014

DOI: $10.3892 / \mathrm{mmr} .2014 .2134$

\begin{abstract}
The aim of the present study was to examine the expression of integrin $\beta 1$ in squamous cell carcinoma (SCC) of the cervix and its association with the clinicopathological features of patients. The expression of integrin $\beta 1$ in 87 SCC cervical tissues and 32 normal cervical tissues was detected using an enzyme-linked immunosorbent assay, western blot analysis and the immunohistochemical streptavidin-peroxidase method. Integrin $\beta 1$ expression was greater in SCC cervical tissues compared with that in normal cervical tissues $(\mathrm{P}<0.05)$, and its mean expression level in the SCC cervical tissues was also markedly higher compared with that in the normal cervical tissues $(\mathrm{P}<0.05)$. In terms of the association between the expression of integrin $\beta 1$ with clinicopathological features, patients with stage IIA SCC had higher integrin $\beta 1$ positive rates compared with patients with stage I SCC $(\mathrm{P}<0.05)$. The integrin $\beta 1$ positive rates in SCC tissues with histological grade 3 were also significantly higher than that in the SCC tissues with histological grade $1(\mathrm{P}<0.05)$. Furthermore, patients with cervical SCC with lymph node metastasis showed increased integrin $\beta 1$ positive expression compared with those without lymph node metastasis $(\mathrm{P}<0.05)$. In conclusion, the expression of integrin $\beta 1$ protein in cervical SCC tissues was significantly higher than that in the normal cervical tissues, and it increased with the clinical stage and the degree of malignancy.
\end{abstract}

\section{Introduction}

Cervical cancer is a common gynecological cancer and, in recent years, the frequency has increased, particularly in younger individuals $(1,2)$. Squamous cell carcinoma (SCC) of the cervix is one of the most common pathological types of

Correspondence to: Professor Xi-Guang Mao, Department of Gynecology, Affiliated Hospital of Luzhou Medical College, No. 25 Taiping Road, Luzhou, Sichuan 646000, P.R. China

E-mail: xiguangmaocn@163.com

Key words: integrin $\beta 1$, squamous carcinoma of the cervix, tumor metastasis cervical cancer. Local invasion and lymph node metastasis is the primary disseminating mechanism in cervical cancer, and the main cause of mortality. There are numerous factors that affect the prognosis of cervical cancer, including clinical staging, pathological type, tumor size, invasion depth, lymph node metastasis, patient age and body condition (3). At present, the mechanisms underlying cervical cancer invasion and metastasis are not yet clearly understood. Certain factors that are involved in tumor invasion and metastasis have been identified, including adhesion molecules. Adhesion molecules are glycoproteins located on the cell surface or in the cell matrix. Following the binding of the receptor to the ligand, they are involved in numerous cellular processes, including cell-cell adhesion, cell-matrix adhesion, cell recognition, activation and signal transduction, as well as the promotion of cell proliferation, differentiation, stretching and movement. This is the molecular basis of a series of important physiological and pathological processes, including the immune response, inflammation, tumor metastasis and wound healing.

There are several classes of adhesion molecules, including integrins, laminins and collagens (4). Integrins are important in tumor growth, differentiation and metastasis by mediating cell-cell or cell-extracellular matrix adhesion and signal transduction (5). Integrin $\beta 1$, a subunit of integrins, is involved in the regulation of various physiological and pathological processes. Integrin $\beta 1$ regulates cell growth and differentiation and promotes cell migration, proliferation and information delivery, as well as induces the expression of tumor-associated genes. Thus, it may be involved in tumor invasion and metastasis $(6,7)$. In the present study, the association between the expression of integrin $\beta 1$ in SCC cervical tissues as well as tumor invasion and metastasis was investigated, in order to provide a basis for the diagnosis and prognosis of SCC of the cervix.

\section{Patients and methods}

Patients and tumor samples. A total of 87 patients with SCC of the cervix (between 23 and 71 years of age; mean age 41.84 years) undergoing radical hysterectomy and pelvic lymphadenectomy at the Department of Gynecology, Affiliated Hospital of Luzhou Medical College (Luzhou, Sichuan, China), between January 2010 and June 2012, were included in the present study. The present study was conducted in accordance 
with The Declaration of Helsinki and with approval from the Ethics Committee of Luzhou Medical College. Written informed consent was obtained from all participants.

Tumor specimens were obtained from the macroscopic lesions of the excised tissues immediately following surgery. Approximately $1 \times 1 \times 0.5 \mathrm{~cm}^{3}$ samples were collected in sterile freezing tubes and frozen in liquid nitrogen until analysis. The remaining tissue was sent to the Department of Pathology at the Affiliated Hospital of Luzhou Medical College for routine pathological examination. It was confirmed histopathologically that 24 patients had pelvic lymph node metastasis, whilst 63 patients did not have pelvic lymph node metastasis. According to the clinical staging established by the International Federation of Gynecology and Obstetrics (2009), patients can be clinically staged as stage I B1 $(n=23)$, stage I B2 $(\mathrm{n}=27)$, stage II A1 $(\mathrm{n}=24)$ and stage II A2 $(\mathrm{n}=13)$. Patients can also be classified as G1 $(n=43), G 2(n=21)$ and G3 $(n=23)$ histological types. Normal cervical tissues from 32 patients who underwent hysterectomy at the same period due to uterine fibroids were collected as the control group. The patients in the control group were between 37 and 67 years of age and had a mean age of 44.02 years. Normal specimens were also sampled at a volume of $\sim 1 \times 1 \times 0.5 \mathrm{~cm}^{3}$ from the columnar junction site of the cervix immediately following surgery, collected in sterile freezing tubes and frozen in liquid nitrogen until analysis. The remaining tissue was also sent to the Department of Pathology for routine pathological examination. No statistical difference in the mean age between the two groups was observed $(\mathrm{P}>0.05)$.

Total protein extraction and enzyme-linked immunosorbent assay (ELISA). Tumor tissues and normal cervical tissues were homogenized in ice-cold extraction buffer using a Polytron ${ }^{\circledR}$ homogenizer (Kinematica, Lucerne, Switzerland) at $89,000 \mathrm{x} \mathrm{g}$ for $1 \mathrm{~min}$, followed by centrifugation at $15,000 \mathrm{xg}$ for $20 \mathrm{~min}$ at $4^{\circ} \mathrm{C}$. The supernatant was then collected and its protein concentration was measured using a bicinchoninic acid (BCA) Protein Assay kit (Pierce Biotechnology, Inc., Rockford, IL, USA).

Integrin $\beta 1$ expression levels in the tumor tissue extracts and the normal cervical tissue extracts were detected using the double antibody sandwich ELISA method. The absorbance at $450 \mathrm{~nm}$ was read using a Bio-Rad Microplate Reader 550 (Bio-Rad, Hercules, CA, USA) and analyzed using the Skanit Software 2.2.1. The relative concentration of integrin $\beta 1$ was calculated by plotting its optical density (OD) value on a standard curve.

Western blot analysis. The quantity of integrin $\beta 1$ in tissue extracts was evaluated using western blot analysis. Equal amounts of total protein extracts were loaded onto an SDS-PAGE and the proteins were separated. The proteins were then transferred onto a nitrocellulose membrane and treated with mouse anti-human integrin $\beta 1$ monoclonal antibody (1:100; Santa Cruz Biotechnology, Inc., Santa Cruz, CA, USA), followed by incubation with horseradish peroxidase-conjugated goat anti-mouse immunoglobulin $\mathrm{G}$ (1:5,000; OriGene Technologies Inc., Beijing, China). $\beta$-actin (1:2,000; Kang Chen Co., Ltd., Shanghai, China) was used as an internal reference. The specific bands of integrin $\beta 1$ and $\beta$-actin on the membranes were detected using an enhanced chemiluminescent method (Pierce Co., Ltd., Waltham, MA, USA) according to the manufacturer's instructions. The bands were scanned using a gel-imaging system (Bio-Rad 2000; Bio-Rad) and analyzed using Quantity One software. The OD value of the integrin $\beta 1$ protein was calibrated against that of $\beta$-actin, in order to calculate the expression level of integrin $\beta 1$ in the tissue extracts.

Immunohistochemistry. Surgical specimens were fixed with 4\% phosphate-buffered paraformaldehyde and embedded in paraffin, prior to being cut into $4-\mu \mathrm{m}$ sections. The sections were deparaffinized and heated in antigen retrieval buffer $(10 \mathrm{mM}$ citric acid; $\mathrm{pH} 6.0$ ) at $98^{\circ} \mathrm{C}$ for $20 \mathrm{~min}$. The sections were cooled naturally to room temperature prior to being incubated with mouse anti-human integrin $\beta 1$ monoclonal antibody (1:50) or phosphate-buffered saline as a negative control at $4^{\circ} \mathrm{C}$ overnight. Then, the sections were treated using a streptavidin-peroxidase (SP) kit according to the manufacturer's instructions. Counter staining was performed using hematoxylin (Dako, Glostrup, Denmark) and then observed under a light microscope (Olympus Co., Ltd., Tokyo, Japan). The specimens were considered to be positive for integrin $\beta 1$ if punctate cellular granules of brown were observed in the cytoplasm or the cellular membrane, and if the proportion of the positive cells was at least $>10 \%$, as previously described (with slight modifications) (8). Five fields were randomly selected and scanned at high power (magnification, $\mathrm{x} 400$ ) and were used to calculate the mean proportion of positive cells. According to the proportion of positive cells identified, the specimens were classified as follows: $\leq 10 \%-; 10-25 \%+$; $25-50 \%++$ and $\geq 50 \%+++$.

Statistical analysis. Statistical analysis was performed using the SPSS v11.5 statistical software (SPSS, Inc., Chicago, IL, USA). The Chi-square test and t-tests were used in the present study. $\mathrm{P}<0.05$ was considered to indicate a statistically significant difference.

\section{Results}

Total protein content. SCC cervical tissues and normal cervical tissues were cut into sections, followed by cell homogenization. The total cellular protein was extracted and the protein content was detected with a microplate reader using the BCA method. As shown in Table I, the mean total protein content in SCC cervical extracts and normal cervical extracts was $7.47 \pm 0.38$ and $3.59 \pm 0.23 \mu \mathrm{g} / \mathrm{ml}$, respectively, with a significant difference observed between the two groups $(\mathrm{P}<0.05)$.

ELISA. The concentration of integrin $\beta 1$ in the SCC and the normal cervical extracts was detected using ELISA and the results are shown in Table II. The mean integrin $\beta 1$ concentration in the SCC cervical extracts was $28.74 \pm 1.62 \mathrm{ng} / \mathrm{ml}$, which was markedly higher than that in the normal cervical extracts $(17.15 \pm 1.38 \mathrm{ng} / \mathrm{ml} ; \mathrm{P}<0.05)$.

Western blot analysis. Integrin $\beta 1$ expression was also detected in tissue extracts using western blotting. Integrin $\beta 1$ expression was found to be elevated in SCC cervical tissues compared with that in normal cervical tissues (Fig. 1). The bands were analyzed using Image Quat4.4 analysis software and integrin $\beta 1$ exhib- 
Table I. Total protein content in the SCC cervical extracts and the normal cervical extracts.

\begin{tabular}{lcccc}
\hline Tissue & Total cases $(\mathrm{n})$ & $\begin{array}{c}\text { Highest value } \\
(\mu \mathrm{g} / \mathrm{ml})\end{array}$ & $\begin{array}{c}\text { Lowest value } \\
(\mu \mathrm{g} / \mathrm{ml})\end{array}$ & $\begin{array}{c}\text { Mean total protein } \\
\text { content }(\mathrm{x} \pm \mathrm{sd})\end{array}$ \\
\hline SCC cervical tissue & 87 & 8.05 & 6.97 & $7.47 \pm 0.38^{\mathrm{a}}$ \\
Normal cervical tissue & 32 & 3.94 & 3.01 & $3.59 \pm 0.23$ \\
\hline
\end{tabular}

${ }^{\mathrm{a}} \mathrm{P}<0.05$, comparison of mean total protein contents between SCC and normal cervical extracts. SCC, squamous cell carcinoma.

Table II. Integrin $\beta 1$ concentration in the SCC cervical extracts and normal cervical extracts.

\begin{tabular}{lcccc}
\hline Group & Total cases $(\mathrm{n})$ & $\begin{array}{c}\text { Lowest value } \\
(\mathrm{ng} / \mathrm{ml})\end{array}$ & $\begin{array}{c}\text { Highest value } \\
(\mathrm{ng} / \mathrm{ml})\end{array}$ & $\begin{array}{c}\text { Mean integrin } \beta 1 \\
\text { concentration } \\
(\mathrm{ng} / \mathrm{ml} ; \mathrm{x} \pm \mathrm{sd})\end{array}$ \\
\hline SCC & 87 & 22.36 & 34.17 & $28.74 \pm 1.62^{\mathrm{a}}$ \\
Normal control & 32 & 10.29 & 20.31 & $17.15 \pm 1.38$ \\
\hline
\end{tabular}

${ }^{\mathrm{a}} \mathrm{P}<0.05$, comparison of mean integrin $\beta 1$ concentrations between SCC and normal cervical extracts. SCC, squamous cell carcinoma.

Table III. Quantitative analysis of the integrin $\beta 1$ expression bands in the two groups.

\begin{tabular}{lcccc}
\hline Groups & Total cases (n) & Positive cases (n) & Positive rate (\%) & Expression levels (x \pm sd) \\
\hline SCC & 87 & 79 & 91 & $0.98 \pm 0.11^{\mathrm{a}}$ \\
Normal control & 32 & 5 & 16 & $0.45 \pm 0.15$ \\
\hline
\end{tabular}

${ }^{\mathrm{a}} \mathrm{P}<0.05$, statistical difference vs. the normal control group. SCC, squamous cell carcinoma.

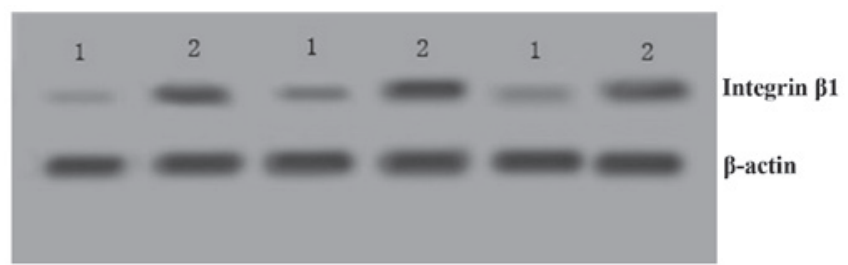

Figure 1. Integrin $\beta 1$ expression in (1) normal and (2) squamous cell carcinoma cervical tissues detected using western blot analysis.

ited a significantly increased expression in SCC cervical tissues $(0.98 \pm 0.11)$ compared with that in normal cervical tissues $(0.45 \pm 0.15 ; \mathrm{P}=0.029$; Table III).

Immunohistochemistry. Due to the high expression of integrin $\beta 1$ in SCC cervical tissues, its location was also determined using immunohistochemical analysis. Moderate to strong cytoplasmic immunoreactivity for integrin $\beta 1$ was identified in the foci of the SCC samples. It was primarily located in the cancer cells and no expression was observed in the mesenchymal cells (Fig. 2). Integrin $\beta 1$ expression was distributed unevenly in the cancer nest, with strong expression observed around the edges and weak expression in the center. In the 87 specimens, 83 of the samples expressed integrin $\beta 1$, accounting for $95.4 \%$. Uniform cytoplasmic expression of integrin $\beta 1$ was observed in the lymph node with metastasis, however, not in the lymph node without metastasis. By contrast, only two cases showed a weak expression of integrin $\beta 1$ in the 32 cases of normal cervical tissues $(6.25 \%)$, which was significantly less than that in SCC tissues ( $\mathrm{P}=0.005$; Table IV).

Association between integrin $\beta 1$ and clinicopathological factors. No significant association was identified between integrin $\beta 1$ expression and patient age $(\mathrm{P}=0.082)$. However, integrin $\beta 1$ expression was significantly correlated with the clinical stage, histological type and lymph node metastasis. All 37 SCC stage IIA cases were integrin $\beta 1$-positive, whilst 46 out of the 50 cases of SCC in stage I were integrin $\beta 1$-positive, which was significantly different $(\mathrm{P}=0.034)$. In terms of histological types, the integrin $\beta 1$-positive rate in $\mathrm{G} 3$ $(100 \% ; 23 / 23)$, G2 $(95.24 \% ; 20 / 21)$ and G1 $(93.02 \% ; 40 / 43)$ was significantly different from each other $(\mathrm{P}=0.016)$. In the patients with lymph node metastasis $100 \%$ of the cases $(24 / 24)$ were integrin $\beta 1$-positive, however, only $93.65 \%$ were integrin $\beta 1$-positive in the patients without lymph node metastasis, which was significantly different $(\mathrm{P}=0.029$; Table V).

\section{Discussion}

Cervical cancer is the second most common type of malignant tumor in females. It results from the abnormal proliferation 
Table IV. Number of positive cells expressing integrin $\beta 1$ in the two groups.

\begin{tabular}{lcccc}
\hline & & \multicolumn{3}{c}{ Integrin $\beta 1$ expression } \\
\cline { 3 - 5 } Group & Total cases $(\mathrm{n})$ & - & + & ++ \\
\hline SCC & 87 & 4 & 8 & 44 \\
Normal control & 32 & 30 & 2 & 0 \\
\hline
\end{tabular}

Proportion of positive cells identified were classified as follows: $\leq 10 \%-; 10-25 \%+; 25-50 \%++$ and $\geq 50 \%+++$. SCC, squamous cell carcinoma.

Table V. Association between integrin $\beta 1$ expression and clinicopathological parameters in patients with squamous cell carcinoma.

\begin{tabular}{|c|c|c|c|c|c|c|}
\hline \multirow[b]{2}{*}{ Variable } & \multirow[b]{2}{*}{ Patient (n) } & \multicolumn{4}{|c|}{ Integrin $\beta 1$ expression } & \multirow[b]{2}{*}{ P-value } \\
\hline & & - & + & ++ & +++ & \\
\hline \multicolumn{7}{|l|}{ Age (years) } \\
\hline$\geq 40$ & 55 & 3 & 5 & 28 & 19 & \multirow[t]{2}{*}{0.082} \\
\hline$<40$ & 32 & 1 & 3 & 16 & 12 & \\
\hline \multicolumn{7}{|l|}{ Clinical staging } \\
\hline I & 50 & 4 & 1 & 31 & 14 & \multirow[t]{2}{*}{0.034} \\
\hline IIA & 37 & 0 & 7 & 13 & 17 & \\
\hline \multicolumn{7}{|l|}{ Histological type } \\
\hline Well (G1) & 43 & 3 & 5 & 26 & 9 & \multirow[t]{3}{*}{0.016} \\
\hline Moderate (G2) & 21 & 1 & 1 & 11 & 8 & \\
\hline Poor (G3) & 23 & 0 & 2 & 7 & 14 & \\
\hline \multicolumn{7}{|c|}{ Pelvic lymph node metastasis } \\
\hline Positive & 24 & 0 & 4 & 9 & 11 & \multirow[t]{2}{*}{0.029} \\
\hline Negative & 63 & 4 & 4 & 25 & 20 & \\
\hline
\end{tabular}
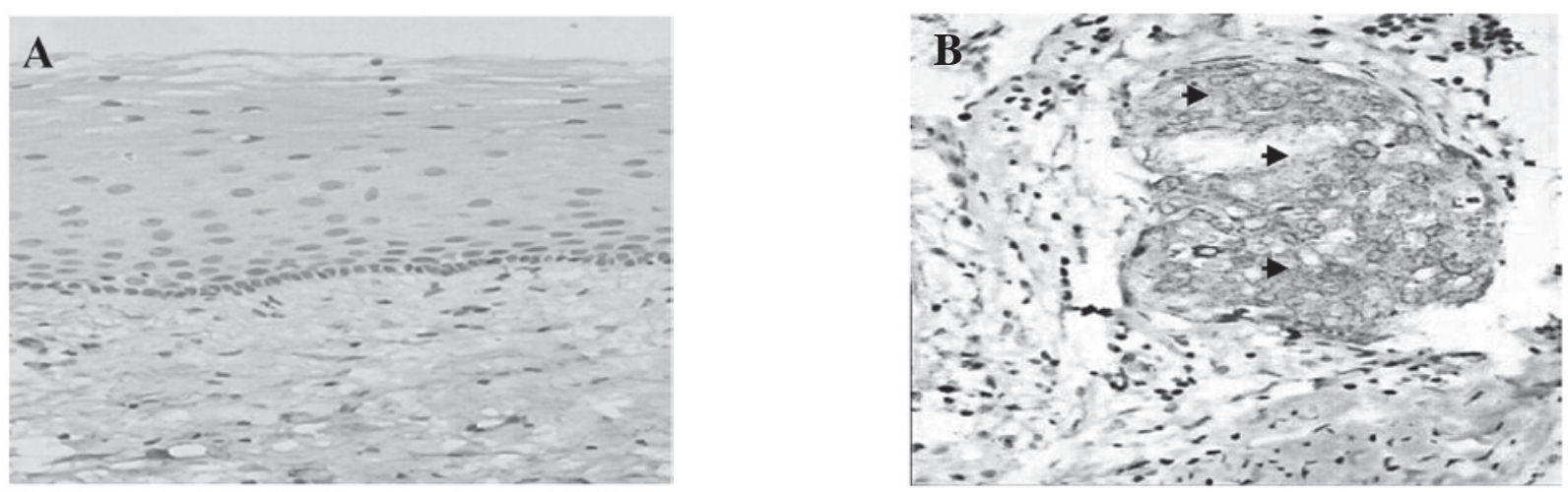

Figure 2. Expression of integrin $\beta 1$ in (A) normal and (B) squamous cell carcinoma cervical tissues (the arrow indicates the expression of integrin $\beta 1$ ). Streptavidin-peroxidase staining (magnification, $\mathrm{x} 200)$.

of differentiated cells, which are genetically unstable. Local invasion and lymph node metastasis is the main mechanism for metastasis in cervical cancer (9). Cell adhesion molecules are important in the development of cervical cancer. They bind to their ligand in the extracellular matrix and mediate cell-cell and cell-extracellular matrix communications, and, therefore, they are important factors in the communication between cells and the surrounding tissues (10). Integrins are an important class of cell adhesion molecules composed of an $\alpha$ subunit and a $\beta$ subunit, connected by a non-covalent bond. Integrin $\beta 1$ is a receptor that is widely distributed on the surface of a number of different cell types, and it affects cell morphology, proliferation, differentiation, migration and the synthesis of certain macromolecules through binding to its ligand in the extracellular matrix. It is also involved in cell signal transduction and regulates tumor angiogenesis and other physiological 
and pathological processes. Thus, integrin $\beta 1$ is important in maintaining the integrity of tissues and promoting cell proliferation, invasion and metastasis of tumors (11-13). Integrin $\beta 1$ is also involved in cell matrix degradation, abnormal adhesion and numerous other processes through the transmission of cellular signals, the regulation of cytoskeleton and the alteration of gene expression, and therefore is closely associated with tumor invasion (14).

In the present study, ELISA was used to detect the expression of integrin $\beta 1$ protein in SCC and normal cervical extracts. It was found that the expression of integrin $\beta 1$ protein in SCC cervical tissues was significantly higher than that in normal cervical tissues $(\mathrm{P}=0.034)$. Furthermore, western blotting was used to determine the expression of integrin $\beta 1$ protein in SCC tissues and normal cervical tissues. The positive rate of integrin $\beta 1$ protein in normal cervical tissues compared with SCC cervical tissues was significantly different ( $16 \%$ vs. $91 \%$, respectively; $\mathrm{P}=0.029$ ), which indicates that the overexpression of integrin $\beta 1$ protein may promote cervical epithelial cells to enter into the cell cycle and overproliferate and thereby lead to tumor formation. Certain studies have demonstrated that the increased expression of integrin $\beta 1$ leads to the migration of stem cells out of the basement membrane and entrance into the cell cycle, subsequently promoting cell proliferation and migration, as well as the transmission of cellular signals, resulting in tumorigenesis (15-17). Song et al (18) found that the expression of integrin $\beta 1$ during the $S$ phase of the cell cycle was significantly higher than that during the G1 phase, suggesting that integrin $\beta 1$ may promote cell proliferation. The increased binding of integrin $\beta 1$ to its ligand in the extracellular matrix may enhance cell signaling pathways, including p53 and EGF, as well as other signaling pathways. This may promote abnormal cell proliferation and affect the control of cell growth and differentiation, consequently leading to tumor growth (19-21). In the present study, using ELISA and western blot analysis, it was found that the expression of integrin $\beta 1$ protein was greater in SCC cervical tissues. The increased expression of integrin $\beta 1$ protein in cervical cancer also enhances the adhesion of tumor cells to the extracellular matrix, facilitating tumor cell migration through the basement membrane and into the surrounding tissue. As a result, invasion and metastasis occurs.

Detection of integrin $\beta 1$ using the SP immunohistochemical method revealed that the expression of integrin $\beta 1$ protein in stage IIA SCC was significantly higher than that in stage $\mathrm{I}(\mathrm{P}=0.011)$. It was also significantly different between that in SCC with histological type G3 and G1 $(\mathrm{P}=0.025)$. Patients with pelvic lymph node metastasis had a significantly higher positive rate of expression of integrin $\beta 1$ compared with patients without pelvic lymph node metastasis $(\mathrm{P}=0.044)$. All these results demonstrated that integrin $\beta 1$ expression in SCC was associated with the clinical stage, histological type and lymph node metastasis, indicating that the occurrence and development of SCC is closely associated with integrin $\beta 1$. With the stimulation of certain factors, the abnormally increased integrin $\beta 1$ binds to its ligand in the basement membrane and promotes the release of matrix metalloproteinases (MMPs) and other components from tumor cells, which damage and degrade the basement membrane, allowing tumor cells to break through the basement membrane and infiltrate into the stroma $(22,23)$. Our previous study revealed that in the extracellular matrix of SCC, the expression of MMP-2, which is known to degrade the extracellular matrix, increased significantly (24). Furthermore, microvessel density in tumor tissues was also enhanced, providing nutritional support for tumor cells, which contributes to the invasion and metastasis of tumor cells into the surrounding normal tissues.

Integrins are associated with the occurrence and development of various types of tumor $(25,26)$. The present study revealed, using an ELISA assay, that the levels of integrin $\beta 1$ protein in SCC tissues increased, and this was confirmed using western blot analysis and polymerase chain reaction. Using the immunohistochemical SP method it was found that, along with the increase of clinical stage and pathological grade as well as the occurrence of lymph node metastasis, the expression of integrin $\beta 1$ protein also increased, which is consistent with previous results (27). This indicates that during the occurrence and development of SCC, the increased expression of integrin $\beta 1$ may promote lesion development.

In conclusion, the expression of integrin $\beta 1$ protein increased abnormally in SCC, suggesting that integrin $\beta 1$ is important in the development of cervical cancer. Therefore, detection of the integrin $\beta 1$ protein may be a useful indicator for assessing the progress, therapeutic efficacy and prognosis of SCC of the cervix.

\section{Acknowledgements}

This study was supported by the Health Department Fund of Sichuan Province, China (07022).

\section{References}

1. Parkin DM, Bray F, Ferlay J and Pissani P: Global cancer statistics 2002. CA Cancer J Clin 55: 74-108, 2005.

2. El-Khatib Z, Tota JE and Kaufmann AM: Progress on human papillomavirus (HPV) infection and cervical cancer prevention in sub-Saharan Africa: highlights of the 27th International Papillomavirus Conference in Berlin, 17-22 September 2011. J Epidemiol Glob Health 2: 99-102, 2012.

3. Shinyo J, Kodama A, Hongo M, Yoshinouchi $M$ and Hiramatsu Y: Heparanase expression is an independent prognostic factor in patients with invasive cervical cancer. Ann Oncol 14: 1505-1510, 2003.

4. Masuda M, Yageta M, Fukuhara H, et al: The tumor suppressor protein TSLC1 is involved in cell-cell adhesion. J Biol Chem 277: 31014-31019, 2002.

5. Boettiger D: Mechanical control of integrin-mediated adhesion and signaling. Curr Opin Cell Biol 24: 592-599, 2012.

6. Humphries MJ: Integrin structure. Biochem Soc Trans 28: 311-339, 2000.

7. Sodek KL, Ringuette MJ and Brown TJ: Compact spheroid formation by ovarian cancer cells is associated with contractile behavior and an invasive phenotype. Int J Cancer 124: 2060-2070, 2009.

8. Zutter MM, Mazoujian G and Santoro SA: Decreased expression of integrin adhesive protein receptors in adenocarcinoma of the breast. Am J Pathol 137: 863-870, 1990.

9. Corcoran J, Dattalo P and Crowley M: Cervical cancer screening interventions for U.S. Latinas: a systematic review. Health Soc Work 37: 197-205, 2012.

10. Shagieva GS, Domnina LV, Chipysheva TA, Ermilova VD, Chaponnier C and Dugina VB: Actin isoforms and reorganization of adhesion junctions in epithelial-to-mesenchymal transition of cervical carcinoma cells. Biochemistry (Mosc) 77: 1266-1276, 2012. 
11. Gruber G, Hess J, Stiefel C, et al: Correlation between the tumoral expression of beta3-integrin and outcome in cervical cancer patients who had undergone radiotherapy. $\mathrm{Br}$ J Cancer 92: 41-46, 2005.

12. Heyder C, Gloria-Maercker E, Hatzmann W, Niggemann B, Zänker KS and Dittmar T: Role of the beta1-integrin subunit in the adhesion, extravasation and migration of T24 human bladder carcinoma cells. Clin Exp Metastasis 22: 99-106, 2005.

13. Van der Flier A and Sonnenberg A: Function and interactions of integrins. Cell Tissue Res 305: 285-298, 2001.

14. Margadant C, Monsuur HN, Norman JC and Sonnenberg A Mechanisms of integrin activation and trafficking. Curr Opin Cell Biol 23: 607-614, 2001

15. Kawahara R, Matsuda $M$ and Mori T: Increase in the number of integrinbeta1-immunoreactive monocyte-lineage cells in experimentally-induced adenomyosis in mice. Life Sci 73: 907-916, 2003.

16. Shie MY and Ding SJ: Integrin binding and MAPK signal pathways in primary cell responses to surface chemistry of calcium silicate cements. Biomaterials 34: 6589-6606, 2013.

17. Sun Y, Cao YW, Lu TC, et al: Cell differentiation during carcinogenesis of cervical epithelia. Ai Zheng 24: 1184-1190, 2005 (In Chinese).

18. Song GB, Qin J, Luo Q, Shen XD, Yan RB and Cai SX: Adhesion of different cell cycle human hepatoma cells to endothelial cells and roles of integrin beta1. World J Gastroenterol 11: 212-215, 2005.

19. Selivanova $\mathrm{G}$ and Ivaska J: Integrins and mutant $\mathrm{p} 53$ on the road to metastasis. Cell 139: 1220-1222, 2009.
20. Fonseca FL, Azzalis LA, Feder D, et al: Adhesion molecules affected by treatment of lung cancer cells with epidermal growth factor. Lung 189: 383-389, 2011.

21. Daves MH, Hilsenbeck SG, Lau CC and Man TK: Meta-analysis of multiple microarray datasets reveals a common gene signature of metastasis in solid tumors. BMC Med Genomics 4: 56, 2011.

22. Wang PH, Ko JL, Tsai HT, et al: Clinical significance of matrix metalloproteinase-2 in cancer of uterine cervix: a semiquantitative study of immunoreactivities using tissue array. Gynecol Oncol 108: 533-542, 2008.

23. Tsai SJ, Hwang JM, Hsieh SC, Ying TH and Hsieh YH: Overexpression of myeloid zinc finger 1 suppresses matrix metalloproteinase-2 expression and reduces invasiveness of SiHa human cervical cancer cells. Biochem Biophys Res Commun 425: 462-467, 2012.

24. Zhan P, Mao X, Dong S, et al: Relationship of expression of integrin $\beta_{1}$ in cervical cancer with microvessel density and its invasion ability. Modern Cancer 16: 417-419, 2008.

25. Zhao Y, Bachelier R, Treilleux I, et al: Tumor alphavbeta3 integrin is a therapeutic target for breast cancer bone metastases. Cancer Res 67: 5821-5830, 2007.

26. Collier ME, Li C and Ettelaie C: Influence of exogenous tissue factor on estrogen receptor alpha expression in breast cancer cells: involvement of beta1-integrin, PAR2, and mitogen-activated protein kinase activation. Mol Cancer Res 6: 1807-1818, 2008.

27. Matsuoka T, Yashiro M, Nishimura S, et al: Increased expression of alpha2beta1-integrin in the peritoneal dissemination of human gastric carcinoma. Int J Mol Med 5: 21-25, 2000. 